from: http://www.health.nsw.gov.au/factsheets/guideline/ pneumo.html (Cited 27 May 2011.)

3. Isaacman DJ, Fletcher MA, Fritzell B, Ciuryla V, Shranz J. Indirect effects associated with widespread vaccination of infants with heptavalent pneumococcal conjugate vaccine (PCV7;Prevenar). Vaccine 2007; 25(13): 2420-7. doi:10.1016/J.VACCINE.2006.09.011

4. Metlay JP, Fishman NO, Joffe M, Edelstein PH. Impact of pediatric vaccination with pneumococcal conjugate vaccine on the risk of bacteremic pneumococcal pneumonia in adults Vaccine 2006; 24(4): 468-75. doi:10.1016/J.VACCINE. 2005.07.095

5. Kellner JD, Vanderkooi OG, MacDonald J, Church DL, Tyrrell GJ, Scheifele DW. Changing epidemiology of invasive pneumococcal disease in Canada, 1998-2007: update from the Calgary-area Streptococcus pneumoniae research (CASPER) study. Clin Infect Dis 2009; 49(2): 205-12. doi:10.1086/599827
6. Sydney West Immunisation Strategy 2010-13. Parramatta: Centre for Population Health; 2010.

7. Dias R, Caniça M. Invasive pneumococcal disease in Portugal prior to and after the introduction of pneumococcal heptavalent conjugate vaccine. FEMS Immunol Med Microbiol 2007; 51(1): 35-42. doi:10.1111/J.1574-695X.2007.00283.X

8. Lynch JP, Zhanel GG. Streptococcus pneumoniae: epidemiology and risk factors, evolution of antimicrobial resistance, and impact of vaccines. Curr Opin Pulm Med 2010; 16(3): 217-25.

9. Harboe ZB, Benfield TL, Valentiner-Branth P, Hjuler T, Lambersten L, Kaltoft M. et al. Temporal trends in invasive pneumococcal disease and pneumococcal serotypes over 7 decades. Clin Infect Dis 2010; 50(3): 329-37. doi:10.1086/ 649872

10. Liñares J, Ardanuy C, Pallares R, Fenoll A. Changes in anitmicrobial resistance, serotypes and genotypes in Streptococcus pneumoniae over a 30-year period. Clin Microbiol Infect 2010; 16(5): 402-10. doi:10.1111/J.1469-0691.2010.03182.X

\title{
Aboriginal identification in Hunter New England infants
}

\author{
Natalie Allan ${ }^{\mathrm{A}}$ and Patrick M. Cashman ${ }^{\mathrm{A}, \mathrm{B}}$ \\ ${ }^{\mathrm{A}}$ Hunter New England Population Health \\ ${ }^{\mathrm{B}}$ Corresponding author. Email: Patrick.Cashman@hnehealth.nsw. \\ gov.au
}

The delayed immunisation of Indigenous children in the first year of life is an important issue in Australia. ${ }^{1}$ The proportion of Aboriginal infants not fully immunised at 12 months of age $(15 \%)$ is over double that of nonAboriginal children $(7 \%)$ in the Hunter New England Local Health District (HNELHD).

In the past when Hunter New England Population Health received Australian Childhood Immunisation Register lists of children overdue for vaccination, Aboriginal children were identified in partnership with local Aboriginal health workers and followed up in an attempt to facilitate more timely future doses of vaccine. However, this meant that children were already overdue at an age when they were most vulnerable to many vaccine-preventable diseases. This 'lesson from the field' describes a new approach to improve both Aboriginal immunisation rates and the recording by health staff of mothers' identification of their baby's Aboriginal status.

The Hunter New England Aboriginal Health Partnership requested that action be taken to close the gap in Aboriginal infant immunisation. The Partnership is an executive steering group with membership consisting of the Chief Executive Officer of the HNELHD and the chairperson or elected representative of each of the nine Aboriginal Community Controlled Health Services in the district. The Partnership aims to improve the health of Aboriginal people in the Hunter New England region by providing leadership, ongoing advice on general health policy, strategic planning, service issues and equity of allocation of resources. The Partnership provides a forum and a process for sharing information and is committed to the practical application of the principles of Aboriginal peoples' self-determination, a partnership approach and intersectoral collaboration. To facilitate immunisation, the Partnership supported the use of newborn data from all routine health service records for the purposes of contacting the child's parents.

Through a new approach to improve the timeliness of Aboriginal infant vaccination the parents of newborn Aboriginal infants are contacted soon after birth by an Aboriginal immunisation officer in the Population Health Unit. The officer facilitates the early linking of mothers with providers of immunisation. The approach also emphasises the importance of the accurate recording by health staff of mothers' identification of their baby's Aboriginal status.

As the program aims to contact the family of Aboriginal infants prior to their first scheduled immunisation, its success depends on the accuracy and completeness of Aboriginal identification recording in newborn datasets. However, the Aboriginal immunisation officer employed to contact the mothers of Aboriginal infants noted that the 
records held by the Community Health Information Management Enterprise (CHIME), the principal inpatient database, were often inaccurate and did not reflect community knowledge. Consequently, this prompted the systematic comparison of recorded Aboriginal identification in two datasets, CHIME and Obstetri $X^{2}$

\section{Methods}

The recorded identification of Aboriginal infants in two health service datasets was compared over a 3-month period, August-October 2010. Data from the NSW Health ObstetriX database were compared to the birth notification data available from the CHIME.

The ObstetriX database is completed in HNELHD maternity units. During the post-natal interview, midwives ask all mothers to nominate whether their baby will identify as Aboriginal and this information is then recorded in the ObstetriX database. Aboriginal births recorded in this database are supplied monthly to the Population Health Unit by the 15 maternity midwifery unit managers in HNELHD to permit follow up by the Aboriginal immunisation officer of these babies' mothers.

CHIME is the principal inpatient database in HNELHD and contains detailed patient demographic information collected during any presentation within the HNELHD. The CHIME data are automated and are available to the Population Health Unit within a few days of birth. However, Aboriginal identification of infants is not verified and defaults to the mother's recorded identity. This system populates all the HNELHD clinical records.

\section{Results}

Less than half $(46 \% ; 72 / 158)$ of newborns were recorded as Aboriginal in both data sets. Fifty-three percent of newborn Aboriginal children (84/158) were only recorded in ObstetriX and 1\% (2/158) only in CHIME.

\section{Discussion}

Accurate recording by health staff of mothers' identification of their baby's Aboriginal status in medical information systems is essential to the success of the initiative linking Aboriginal infants and immunisation service providers. Strategies which allow Aboriginal people to identify themselves assist in the provision of services that can close the gap in health experience. ${ }^{3}$

The discordance between the ObstetriX and CHIME datasets identified by this study resulted in the HNELHD embarking on a program to encourage staff to support more complete identification by Aboriginal clients of the service. A training package for clerical staff who record demographic data was developed. Database managers now routinely compare Aboriginal identification data across databases, a quality measure initiated by this study.

\section{References}

1. Hull BP, Mahajan D, Dey A, Menzies RI, McIntyre PB. Immunisation coverage annual report, 2008. Commun Dis Intell 2010; 34: 241-58.

2. ObstetriX database. NSW Perinatal Data Collection (HOIST). Centre for Epidemiology and Research, NSW Department of Health.

3. Kelaher M, Parry A, Day S, Paradies Y, Lawlor J, Solomon L. Improving the identification of Aboriginal and Torres Strait Islander People in mainstream general practice. August 2010. Lowitja Institute. Available from: http://www. lowitja.org.au/improving-identification-aboriginal-andtorres-strait-islander-people-mainstream-general-practice-0 (Cited 2 June 2011.)

\section{Why are children on the NSW North Coast not being vaccinated against chickenpox?}

\author{
Marianne Trent \\ North Coast Public Health Unit \\ Email: Marianne.Trent@ncahs.health.nsw.gov.au
}

In November 2005, varicella (chickenpox) vaccination administered at 18 months of age was included in the government funded National Immunisation Program for all children born after 1 May 2004. ${ }^{1}$ Each month the former North Coast Public Health Unit received a report on children recorded as overdue to receive the vaccination according to the Australian Childhood Immunisation Register (ACIR). It appeared that a disproportionate number of children aged 20-60 months were recorded as overdue for varicella vaccine.

This study explored why 907 children living in northern New South Wales (NSW) and aged 20-60 months as at April 2010 had received, according to the ACIR, all their other due vaccinations but not varicella vaccination. 